9-27-2013

\title{
The Reciprocity Theory of Rights
}

Follow this and additional works at: http:/ / digitalcommons.osgoode.yorku.ca/ transnationalism_series

\section{Recommended Citation}

"The Reciprocity Theory of Rights" (2013). Legal Philosophy between State and Transnationalism Seminar Series. 58. http://digitalcommons.osgoode.yorku.ca/transnationalism_series/58

This Article is brought to you for free and open access by the Seminars at Osgoode Digital Commons. It has been accepted for inclusion in Legal Philosophy between State and Transnationalism Seminar Series by an authorized administrator of Osgoode Digital Commons. 


\title{
The Reciprocity Theory of Rights ${ }^{1}$
}

\author{
David Rodin
}

This article provides a theoretical account of a central class of moral rights; their normative grounding, the conditions for their possession and forfeiture, and their moral stringency. It argues that interpersonal rights against harm and rights to assistance are best understood as arising from reciprocity relations between moral agents. The account has significant advantages compared with rivals such as the interest theory of rights. By explaining the differential enforceability of rights against harm and rights to assistance, the reciprocity theory helps to refute an argument made by Cecile Fabre that the poor may have a justification for engaging in war against the affluent to compel them to fulfil their duties of assistance to the poor.

We all have rights against certain forms of harm from others, for example I have the right that you not kill or main me. We also have rights to assistance in particular circumstances of need, for example if you were drowning and I could rescue you by throwing a life preserver at no cost to

\footnotetext{
${ }^{1}$ I am extremely grateful to Jonathon Quong, Leif Wenar, Massimo Renzo, Cecile Fabre and an anonymous reviewer for extensive critical comments on this essay.
} 
myself, then you would have the right that I do so. Correlative to these rights are corresponding duties. ${ }^{2}$

Rights have a distinctive stringency, one important feature of which is that typically they can be permissibly enforced. If I infringe a right then I may be subject, in the appropriate circumstances, to three forms of remedial measure: 1) I can be harmed, if necessary, to prevent the infringement (enforcement through self and other-defence); 2) I can be harmed to compensate you for the harm resulting from the infringement (enforcement through restitution); and 3) I can be punished to deter future infringement (punitive enforcement).

There are significant differences between these mechanisms. The permission to engage in defence against breaches of the right not to be harmed is particularly broad in at least two respects. First, rights against

\footnotetext{
${ }^{2}$ Throughout this article I will use the terms 'right not be harmed' and 'right to assistance' (and their cognates 'duty not to harm' and 'duty to assist') in a common sense way consistent with these paradigm examples. I will not address the issue of how the two forms of duty can be distinguished in problem cases, nor how the distinction between duties not to harm duties to assist relates to adjacent distinctions between positive and negative duties and between perfect and imperfect duties. Although these are important issues, they will not materially affect the main lines of argument presented here.
} 
harm can be permissibly enforced through lethal defensive measures when necessary (provided that the breach of right which defensive action averts would inflict a comparable harm). Second, duties not to harm can be enforced through private defensive measures. By this I mean that defence against an unjust harm can be permissibly undertaken by private actors without prior public authorisation. For obvious reasons, one does not need to obtain prior judicial authorisation for engaging in private selfdefence against an imminent threat. ${ }^{3}$

These two features of defensive rights - that they can justify intentional killing, and can be undertaken privately (without the prior consent of a superior authority) - have been important supports of the widely held view that defence against grave and systematic unjust threats of harm can justify war. ${ }^{4}$ In a striking argument, Cecile Fabre extends this logic from rights against harm to rights to assistance. ${ }^{5}$

\footnotetext{
${ }^{3}$ However it is important to note also the limit to private nature of rights of defence: all developed legal systems will subject acts of private defence to post hoc judicial scrutiny.

${ }^{4}$ Self-identifying footnote removed.

${ }^{5}$ Cecile Fabre, Cosmopolitan War, Oxford, Oxford University Press, 2012, Chap 3.
} 
The affluent, she notes have a duty to provide material assistance to the poor. ${ }^{6}$ The basis of this duty, Fabre believes, is the human right, possessed by all, to material resources sufficient to lead a minimally decent life. Those affluent persons who are in a position to provide such resources to the poor without threatening their own prospects to lead a minimally decent life have a duty to do so. ${ }^{7}$ Those who fail to fulfil this duty of assistance are engaged in a wrongful omission, which causes the poor to suffer serious, often life-threatening, unjust harm. Such persons, Fabre claims, are liable to necessary defensive violence to compel them to observe their duty to assist. If violations of the duty to assist are sufficiently grave and systematic, this can form the basis of a just cause

\footnotetext{
${ }^{6}$ As Fabre notes there are different ways in which the affluent could be said to violate the rights of the poor. In S 3.2.1. she argues that the affluent may be morally responsible for the deprivation experienced by the poor, either because they have wrongfully appropriated the property of the poor, or - following an argument made by Hugo Grotius - because the affluent have refused to return property to the common stock for use by the destitute. In this paper I will not address these responsibility-based claims for a duty to the poor. Instead I focus exclusively on duties to assist the poor that are independent of moral responsibility for the poverty.

${ }^{7}$ Cosmopolitan War. 1.2.1.
} 
for a war of subsistence by the poor, or their representatives, against the affluent. $^{8}$

Fabre's argument is premised on the assumption that duties to assist have a comparable stringency to duties not to harm in at least this respect: both duties can be enforced through private lethal defensive action, when their breach would threaten a sufficiently grave harm. Underpinning this presupposition is a particular account of rights - the interest theory as developed by Joseph Raz. This theory is congenial to Fabre's argument because it suggests a fundamental parity between rights against harm and rights to assistance. According to Raz:

' $\mathrm{X}$ has a right' if an only if $\mathrm{X}$ can have rights, and, other things being equal, an aspect of X's well-being (his interest) is a sufficient reason for holding some other person(s) to be under a duty. ${ }^{9}$

Rights against harm and rights to assistance are both equally grounded in the right bearer's interest (on Fabre's telling, their interest in leading a minimally decent life). On this basis it seems natural that the various

\footnotetext{
${ }^{8}$ Ibid. 3.2.3.

${ }^{9}$ Joseph Raz, The Morality of Freedom, Oxford, Oxford University Press, 1986, 166.
} 
forms of right should be equally enforceable when the harm caused by their breach is equivalent. As we might put it: rights are rights.

However, as I will argue in this essay, there are serious problems with the interest theory of rights and the equal enforceability thesis it gives support to. Fabre's unorthodox endorsement of subsistence war is one symptom of this deeper problem in the theory of rights. Before we consider the arguments for this claim, it is Germaine to begin by reflecting on the fact that equal enforceability of rights thesis is in grave tension with commonly held intuitions and standard legal provisions.

In almost all legal jurisdictions, for example, duties to assist are enforced in very different ways to duties not to harm. Every jurisdiction criminalises attacks on the person and attacks on property. However, only a handful of jurisdictions criminalise the failure to provide assistance to others to whom one does not owe a pre-existing duty of care. Moreover, legal duties to assist are only enforced in cases where the obligation to give assistance is extremely undemanding on the duty bearer, and the harm that may be averted is particularly grave.

It is true that citizens in many jurisdictions can be legally compelled to assist others through mandatory participation in collective welfare measures, for example redistributive taxation and social insurance 
schemes. But duties to assist strangers are not enforceable in law through lethal measures and they are not privately enforceable. I am aware of no jurisdiction that provides a justification for private killing, or the threat of killing, in order to compel compliance with a duty to assist, even when such action may be necessary to avert death. Notoriously, a number of jurisdictions even criminalise the unauthorised taking of property required for subsistence.

It is true that the private infringement of property rights can sometimes be justified when necessary to avert a great harm. But this justification is both different to, and weaker than, the justification generated in private defensive action. Consider the classic case of a hiker lost in a storm who breaks into a privately owned cabin in order to save his life. The case has the following features: 1) the hiker is all things considered permitted to break the door of the cabin, and 2) the owner of the cabin would be under a duty to assist the hiker by offering him food and shelter were he present and in a position to do so. Notwithstanding these two features the hiker has the duty to compensate the owner for his loss after the fact. This is not true of standard cases of self-defence in which the party harmed by the defensive action has no right to compensation. This suggests that even when a person is under a legal and moral duty to assist, they may retain a degree of normative entitlement to the resources required to fulfil 
that duty that is quite different to the liability to harm in standard cases of defence. $^{10}$

Now of course, morality is not always congruent with the law, and it may be that these legal provisions are simply unjustified in moral terms (or justifiably deviate from underlying morality). However it is striking that the law accords better with our moral intuitions than Fabre's reading of the interest theory in these cases. Consider, a modified version of Peter Singer's famous example of a man who comes upon a boy drowning in a fountain. ${ }^{11}$ If I were observing the incident from a neighbouring building

${ }^{10}$ The most natural way to explain this difference is to say that the cabin owner (unlike the aggressor in self-defence) retains his right against interference in his property - a right that is justifiably infringed by the hiker. However, as an anonymous reviewer points out, an alternative explanation is that the owner has a complex right of this form: to either not have his door broken, or in cases in which breaking the door is necessary to satisfy a dire need, to be compensated for the breaking of the door. In either case, the cabin owner retains a degree of normative control over the resources needed for assistance of others that is quite different to standard defence cases.

${ }^{11}$ Peter Singer, "Famine, Affluence, and Morality" Philosophy and Public Affairs, 1.1 1972, 229-243. 
and I possessed a high powered rifle and a loud-hailer, then it seems that I would not be permitted to shoot the man dead if he refused to rescue the child and doing so was necessary to save the child's life (suppose that the man's body would fall into the fountain enabling the child to clamber out). Moreover, it seems doubtful that I would even be permitted to threaten the passing man with death if he did not rescue the child. ${ }^{12}$ This is the case even if we accept that the passing man is under a duty to rescue the child.

${ }^{12}$ Jon Quong has objected that these examples involve opportunistic harming (in the sense employed by Warren Quinn) whereas certain violent acts visited on the affluent by the poor to compel them to fulfill their duties would merely involve eliminative harming. Many theorists believe that opportunistic harming is more difficult to justify than eliminative harming. However, as Quong concedes, the example can be reformulated to involve only eliminative harming. An example would be if we suppose that the man at the fountain were holding the life preserver, and shooting him would cause him to release his grip allowing it to fall into the fountain. Moreover, many acts undertaken by the poor in the course of a subsistence war, as envisaged by Fabre, would clearly be acts of opportunistic harming: for example threatening the affluent with violence if they did not fulfill their duties to assist. (On the opportunistic/eliminative distinction see Warren Quinn, “Actions, Intentions, and Consequences: The Doctrine of Double Effect," Philosophy \& Public Affairs 18 (1989): 33451, 344; Jonathan Quong, “ Killing in Self-Defense”, Ethics, 2009, Vole 119, 507-537, 525ff.) 
These moral intuitions and legal precedents strongly suggest that there are significant differences between the enforceability of rights to assistance and rights against harm, and that rights to assistance are, in general, neither enforceable through lethal means, nor are they generally privately enforceable. If rights to assistance are not enforceable in these ways, then Fabre's argument in favour of subsistence wars must fail. This is because war necessarily involves lethal and private enforcement of rights (war is private enforcement in the sense that it is a form of selfhelp - there is no superior public authority to give prior consent).

However, we do not want deep issues in the theory of rights to be settled by appeal to intuition alone. We should aspire to a theoretical explanation for why duties not to harm ground significantly stronger rights of enforcement compared with duties to assist. Given the significant intuitive differences between rights against harm and rights to assistance, what (if anything) can explain and justify them? I will argue that this explanation can be provided by what I will call the reciprocity theory of rights.

The Reciprocity theory of rights

An important class of interpersonal rights are best understood as deriving from reciprocity relations between moral agents. The difference between 
rights to assistance and rights against harm stem from the different ways the two forms of right (and their correlative duties) arise out of moral reciprocity relations. Rights against harm are (in part) grounded in reciprocal compliance with metal obligations. Rights to assistance are (in part) grounded in reciprocal expectations of future compliance with metal obligations. This difference explains the greater stringency of rights against harm compared with rights to assistance, even when the breach of both rights would lead to equivalent harms.

The reciprocity theory begins from a basic observation about the genesis of rights: agents can come to possess rights when they comply with the obligations generated by the rights and status of others. Rights, in other words, may arise out of moral reciprocity. The mechanism by which rights are generated through reciprocity is one of the most basic and deeply rooted in moral psychology - the requirement to give respect and consideration to those who give respect and consideration to us. Rights are in this way mutually reinforcing, and this is one of the most important and efficacious features of a system of rights. In the following sections I will demonstrate how reciprocity can provide a powerful account of rights against harm and of rights to assistance.

Before doing so, let me first clarify what kind of theory the reciprocity account aspires to be. First it is not a formal analysis of the concept of 
rights; that is to say it is not an account of what rights are. Neither is it a theory designed to settle the question of what rights there are, in the sense of specifying a set of necessary and sufficient conditions for the possession of a right by an agent. This is because, as I will indicate bellow, not all rights (and not even all moral rights) are grounded in reciprocity relations. A complete theory of rights will therefore need to be pluralist, with the reciprocity theory forming one explanatory element among others.

Rather the reciprocity account is a normative and justificatory theory. My claim is that for a class of centrally important rights reciprocity provides the best explanation for why we possess these rights and why they possess the normative features they do. ${ }^{13}$ I will be especially concerned with explaining their stringency, and their liability to forfeiture in certain situations.

I begin with rights against harm. Consider a paradigmatic right against harm, such as the right not to be killed (or its logical equivalent, the duty

${ }^{13}$ As I will indicate bellow there are unanswered questions as to precisely what is the extent of the class of rights explained by reciprocity, but it certainly includes some of our most important human rights including basic security rights and rights to assistance in dire need. 
not kill ). This right is best explained by mutually supporting reciprocity relationships between moral agents: I have the right that you not kill me because and to the extent that I comply with your right that I not kill you. Similarly, you have the right that I not kill you because and to the extent that you comply with my right that you not kill me.

As is suggested by the 'because' and 'to the extent' clauses in this specification, the reciprocity theory has two components. First reciprocity functions as the justificatory ground of the right - it explains why we have the right and, crucially, as I will explain bellow, why it has the stringency it does. Second reciprocity provides an account of the conditions for possession and loss of the right. Both components are necessary features of a satisfactory normative theory of rights. However, the latter has in general been poorly served by existing accounts of rights. A significant benefit of the reciprocity theory is that it provides a better account than rivals of the conditions for possession and loss of rights and duties. Let us begin here.

One of the most important features of rights is that they are dynamic in nature. By this I mean that rights are capable of altering their 
configuration over time in determinate ways. ${ }^{14}$ As we have already noted, persons who have a right against being harmed can sometimes become liable to suffer harm in the course of defensive, restorative and punitive action designed to remedy a breach or threatened breach of rights for which they are responsible. In each of these cases, an agent's right against harm becomes transformed into a limited liability to suffer harm. When this happens we typically say that the right in question has been forfeit. ${ }^{15}$ On standard accounts, an agent forfeits rights (and thereby

${ }^{14}$ Note that my usage here differs from that of Joseph Raz, who uses the term 'dynamic' to refer to his supposition that rights can serve as the ground of future duties in ways that may be unforeseen. See The Morality of Freedom, supra, 171.

${ }^{15}$ There is an alternative tradition according to which rights can never be forfeit. Instead rights are assumed to possess a complex specification as to their scope, which entails that they do not apply in situations in which it is necessary to harm a rights holder to remedy a wrongful act for which he is responsible. However, as I have argued elsewhere, nothing material hinges on whether we adopt the forfeiture or specification terminology (self-identifying footnote removed). Any claim about the forfeiture of rights can be rephrased without loss as a claim about specification and vice versa. All the arguments that I here employ utilising the terminology of forfeiture can be rephrased mutatis mutandis using specification terminology. 
becomes liable to harm) by infringing or threatening to infringe certain significant rights of others.

A critical test for any theory of rights is that it coherently account for both the conditions for the possession of rights and the conditions for their forfeiture. This is a task that the interest theory of rights in particular has great difficulty in performing. The reason is that the interest theory fails to account for the fact that conditions for the possession of a right and conditions for its forfeiture are necessarily correlative. I will call this requirement 'the forfeiture principle' and it can be formally specified as follows:

If $\mathrm{x}$ is a necessary condition for the possession of $\mathrm{y}$, then the absence of $\mathrm{x}$ is a sufficient condition for the forfeiture of $y$.

Similarly

If $\mathrm{x}$ is a sufficient condition for the forfeiture of $\mathrm{y}$, then the absence of $\mathrm{x}$ is a necessary condition for the possession of $y .{ }^{16}$

The forfeiture principle articulates a perfectly general requirement on the relationship between the possession conditions and the forfeiture

\footnotetext{
${ }^{16}$ Forfeiture here is not assumed to presuppose fault on the part of the forfeiting party. Roughly speaking forfeiture is the non-consensual loss of a right due to a failure to comply with some standard or requirement.
} 
conditions of any right or object. Utilising it we can easily show that possessing an interest in $\mathrm{x}$ is neither a necessary nor a sufficient condition for possessing a right to $\mathrm{x}$.

Take each claim in turn. If we accept (along with standard accounts) that responsibly infringing certain rights of others is a sufficient condition for forfeiting a right against necessary and proportionate harm inflicted in the course of defensive, restorative, or punitive action, then it must be the case that not infringing the rights of others is a necessary condition for possessing the right against being harmed in that way. It follows that a person's interest in avoiding those harms is not a sufficient condition for possessing the right against that harm. In central cases, therefore, possessing an interest in $\mathrm{x}$ is not sufficient for possessing a right to $\mathrm{x}$. Interest theorists, of course, have long acknowledged that possessing an interest in $\mathrm{x}$ is not sufficient for having a right to $\mathrm{x}$ (for example my interest in the $\$ 1000$ in your bank account is not sufficient to generate a right to it). But the interest theory is committed to the narrower claim that where a genuine right to $\mathrm{x}$ exists, the right holder's interest in $\mathrm{x}$ is a sufficient explanation for his possession of the right. Indeed, as we have already seen, for Raz it is part of the definition of rights that "an aspect of X's wellbeing (his interest) is a sufficient reason for holding some other 
person(s) to be under a duty."17 But the present argument shows this claim to be false. In the case of forfeitable rights (the vast majority of all rights) it is never the case that possessing an interest in $\mathrm{x}$ is a sufficient condition for possessing the right to $\mathrm{x}$. This is because the absence of forfeiture conditions function as a necessary condition for possession of any right.

Turning now to the second claim, it is clearly the case that one can lose one's interest in $\mathrm{x}$ without forfeiting one's right to $\mathrm{x}$. Suppose I have some baby equipment which I no longer need now that my children have grown. The equipment is used and has no financial, sentimental, or option value for me. Indeed, because I have find storage it has a disvalue. If possessing an interest in owning the equipment were a necessary condition for possessing a right to it, then it would follow that I forfeit my right to the equipment when I cease to have an interest in it. Patently I do not.

Of course sophisticated versions of the interest theory such as those of Joseph Raz and Mathew Kramer do not hold that the possession of a right must in all circumstances be in the interest of the right holder, merely that it must in general be true that possessing such a right serves the interests

\footnotetext{
${ }^{17}$ Supra N. 7.
} 
of its bearers. ${ }^{18}$ But this move to what is generally in the interests of persons will not diffuse the current objection. For it is clearly not the case that it is generally in the interests of persons to have property rights over redundant or superfluous objects. In central cases, possessing an interest in $\mathrm{x}$ (by either an individual person or by persons generally) is not a necessary condition for possessing a right to $\mathrm{x}$.

The reciprocity theory, in contrast, conforms to and gains support from the forfeiture principle. We have just seen that if the standard account of the conditions for the forfeiture of a right is correct, then it is a necessary condition for the possession of a right that one not infringe certain rights of others - exactly as the reciprocity account specifies that it is. This is not surprising. The reciprocity theory is a forfeiture-lead account. It derives from taking seriously the dynamic nature of rights; the fact that rights can transform into their Hohfeldian opposites through a process of forfeiture under certain conditions.

How damaging is this challenge to the interest theory? One might argue that the force of the challenge is limited. All that I have shown is that

${ }^{18}$ Joseph Raz, The Morality of Freedom, Oxford, Oxford University Press, 1986, 180; Matthew H. Kramer, "Rights Without the Trimmings" in A Debate Over Rights: Philosophical Enquiries Matthew H. Kramer, Simmonds N.E., and Steiner Hillel, Oxford, Oxford University Press, 200, 94. 
possessing an interest in $\mathrm{x}$ is neither a necessary nor a sufficient condition for possessing a right to $\mathrm{x}$. But this does not show that interests are not the central grounds for the possession of a right. Nothing prevents the interest theorist from accepting that compliance with the rights of others is an independent condition for the possession of a right. Fabre makes this move explicitly in a separate discussion of defensive rights. ${ }^{19}$

Similarly, just because some feature is a necessary condition for the possession of a right, it does not follow that it is the most salient moral ground of the right. Consider an analogy: one forfeits one's medal at the Olympics for failing the mandatory drugs test. It follows that passing the drugs test is a necessary condition for possessing the right to the medal. But it does not follow that the right to possess the medal is most saliently explained by the successful passing of the drugs test. One might suppose that my claim that the right not to be killed is grounded in the reciprocal compliance with the right to life of others makes a similar mistake to the claim that an athlete's right to the medal is grounded in his passing of the drugs test. It confuses a necessary condition for the possession of a right with a sufficient explanation of that right.

But, unfortunately for the interest theorist, these comforting thoughts are

${ }^{19}$ Cecile Fabre, "Permissible Rescue Killing", Proceedings of the Aristotelian Society, Vol. cix, Part 2, 149-164, 153. 
unwarranted. We need to explain how the proposed independent conditions can be coherently integrated into a unified account of the possession and forfeiture of rights. Without such an account the conditions are objectionably ad hoc. In the case of the Olympics we can provide precisely such an integrated account by invoking the conception of fair competition. The two conditions of winning the race and passing the drugs test appear normatively disconnected, but they are in fact integrated at a deeper level: they are both complementary aspects of prevailing in a fair competition.

To account for the possibility of forfeiture, the interest theorist is compelled to posit two conditions for the possession of a right - the (neither necessary nor sufficient) interest condition, and the (necessary) condition of complying with the rights of others. But he cannot provide an account of how the two conditions can be integrated in a coherent explanatory conception, given his underlying theoretical commitments. When an aggressor wrongfully threatens the life of a victim, he has no less an interest in continuing to live than at any other time. Why should the threat he poses to the rights of others undermine his right to life, when it in no way undermines or negates his interest in his own life and welfare? It would be as if the athlete was stripped of his medal for failing a drugs test, when the drug in question gave him no unfair advantage. 
Such a forfeiture condition would be objectionably arbitrary because it is entirely disconnected from our underlying account of the appropriate grounds for possessing a medal. In a similar way, the interest theorist can claim that complying with the rights of others is a necessary condition for the possession of a right, but he can't explain it in the context of a theory that sees rights as based in interests that are sufficient to ground duties. The forfeiture conditions are arbitrary in the context of the broader theory.

Why can't the interest theorist simply say that a right to x exists whenever an agent's interest is sufficient to hold some other person under a duty, but the agent's interest in $\mathrm{x}$ can only be sufficient in this way when he complies with the relevant rights of others. ${ }^{20}$ The answer is that if one accepts that complying with the relevant rights of others is a precondition for an agent to possess a right (holding others to be under a duty), one has thereby abandoned the supposition that the agent's interest - however specified - is sufficient for holding those other persons to be under a duty. After all, the agent's interest in the object of his right is identical before and after the forfeiture. The explanatory work is being done by the condition of compliance, not the interest. To reiterate the point made above, if a right can be forfeit through non-compliance with obligations,

\footnotetext{
${ }^{20} \mathrm{I}$ am indebted to Jon Quong for raising this point.
} 
then it cannot be the case that any interest could ever be sufficient for the possession of that right.

If this line of objection is sound, then the interest theorist faces a stark choice between four inhospitable options. First, he could seek to provide an account of how the proposed normatively disconnected conditions for the possession of a right are in fact coherently integrated at a deeper level (as the drugs test condition for possessing the medal is integrated through a theory of fair competition). But it is far from clear what this deeper account could be, given the resources of the interest theory. Alternatively, he could restrict the interest theory to an analysis of the concept of a right and abandon any normative aspirations (that is to say he could restrict the interest theory to an account of what rights are, and deny that it has any implications for what rights there are or for the substantive normative features of rights). ${ }^{21}$ However, it is clear that mainstream interest theorists such as Joseph Raz have viewed the theory as having both an analytical and a normative function. ${ }^{22}$ Indeed, it would be bizarre if it were not the case. Moreover, restricting the interest theory to a purely analytical domain would forestall its use in substantive

\footnotetext{
${ }^{21}$ I am grateful to Leif Wenar for pushing me to consider this point.

${ }^{22}$ Raz makes this clear at The Morality of Freedom, Oxford, Oxford University Press, 1986, 171-2.
} 
normative argumentation in the way that Fabre, for example, uses it. Third, the interest theorist may abandon the supposition that rights are forfeitable. This course is not impossible, but it is highly costly. It will require the interest theorist to give an account of how harming persons in the course of defensive, restorative, or punitive acts is justified, even though the persons subject to the harm retain a right against being so harmed. This could potentially be achieved by developing an account of how such practices justifiably infringe rights, but such an account will clearly play havoc with central tenets of moral and political theory. Failing these three options, the only alternative is to abandon the central claim of the interest theory - that rights are most basically grounded in interests.

What of the reciprocity theory? Unsurprisingly, it has little difficulty in accounting for the possession and forfeiture conditions of rights. On the reciprocity theory, the conditions for the forfeiture of rights are the inverse of the possession conditions - exactly as the forfeiture principle specifies they must be. If we possess rights because, and to the extent that, we comply with the rights of others, then we can forfeit our rights by infringing the rights of others through our own responsible action.

Interests are not irrelevant to the possession and forfeiture of rights on this account, of course. First, interests play an important role in 
determining the proportionality of permissible harm producing measures in forfeiture contexts. The wrongfulness of a rights-infringing act is in part determined by the extent to which it harms the interests of the injured party, and this in turn informs the permissible limits of remedial action. Can the reciprocity theory provide a deeper explanation for why the forfeiture condition of rights (failing to comply with the rights of others) also provides - through its negation - the possession condition of rights? Yes it can. The explanation is provided by the principle that persons are deserving of respect and consideration because, and to the extent, that they give respect and consideration to others. ${ }^{23}$

This principle has two significant advantages. First, it is attractive in its own right. It links the possession of rights with the fulfilment of responsibilities in an intuitively appealing way: no rights without responsibilities. Second, the principle coheres with the logical structure of rights. Claims, liberties, duties, powers, immunities and the other

\footnotetext{
${ }^{23}$ This raises an important question about why we ought not to torture torturers, rape rapists or (arguably) execute murderers. I believe that the answer is that rights and other obligations owed to persons are not the only moral considerations relevant to how we ought to treat them. There can be compelling reasons not to treat a person in a cruel or inhuman way, even if the person himself lacks rights against such treatment. I develop this idea extensively in "Explaining the Absolute Prohibition on Torture" (unpublished manuscript available on request).
} 
Hohfeldian incidents that constitute the domain are rights are all distinguished by a common feature. They all exist in correlative pairs of Hohfeldian incidents. ${ }^{24}$ This suggests that, at the deepest level, the grounding of rights must lie in features of the relationship between the subject and object of rights; paradigmatically between right holder and duty bearer. Rights cannot arise independently of the normative status and agency of duty bearers and vice versa. The reciprocity theory is designed to give voice to this feature of rights. In this respect it contrasts strikingly with the interest theory, whose account of the grounding of rights is not inter-relational, but unilateral. The interests that this theory supposes to lie at the ground of rights speak solely to the status and normative needs of the rights bearer.

\section{Rights to assistance}

Reciprocity can provide a powerful explanatory account of central rights against harm. But what of rights to assistance? It might be thought that reciprocity can have little to say about rights to assistance, since those rights do not typically arise in relationships of symmetrical reciprocity. When I fulfil your right to assistance, it is rarely the case you are simultaneously assisting me. To be sure there are exceptions. We might

${ }^{24}$ Hohfeld W.N., Fundamental Legal Conceptions As Applied in Judicial Reasoning, Cook W.W. (Ed.), Yale University Press, New Haven, 1919. 
think of two stranded climbers each obligated to assist the other by sharing their body warmth. But such cases are atypical. Indeed, duties to assist normally arise in asymmetries of power and need.

However reciprocity relations can give a persuasive account of a significant class of rights to assistance - an explanation that goes a long way to explaining the central intuitions about stringency and enforceability with which we began. Consider a familiar scene from the life of a frontier community. Farmer John's barn has burned down, and the whole town has come together to rebuild it for him. The townsfolk recognise that they are under a duty to assist the unfortunate Farmer John. Suppose you ask one of those toiling on the new barn, why they are obligated to assist John. They might respond: "well, he would do the same for me if it had been my barn".

What underlies this familiar form of moral reasoning is the following normative principle: when a person acknowledges a duty to assist you in a given circumstance, this can create a duty for you to assist them in comparable circumstances. In other words, duties of assistance can also arise from reciprocity relations. The nature of the reciprocity relation underlying rights to assistance is, however, different to that which underlies rights against harm. As we have seen, rights against harm arise from reciprocity in actual compliance - I have the right that you not kill 
me because I am at this moment complying with your right that I not kill you. Rights to assistance, on the other hand, arise from an expectation of future reciprocal compliance. As we will see bellow, this difference in the forms of reciprocity underlying the two rights can do much work in explaining the intuitive differences between them.

We can test the hypothesis that rights to assistance are grounded in reciprocity relations by applying the forfeiture principle to it. If it is indeed a necessary condition for an agent to possess certain rights to assistance that they acknowledge a duty to assist others in similar circumstances, then those rights of assistance must be forfeitable in cases where the agent fails to recognize the reciprocal duty. In fact, when we examine cases, this is precisely what we find.

We do not normally think of rights to assistance as being forfeitable, but it is clear that they can be. Consider the following. I live an area subject to very cold winters but I can't afford a four-wheel drive car. As a consequence I frequently become stranded in snowdrifts. Each time I do, my neighbour, who drives a brand new Range Rover, zooms past shouting out the window: "get a real car, you bum!" Finally I save up enough money for a set of snow tires. The very first time I drive out with my new tires I pass my neighbour who - having unwisely taken his Ferrari instead of the Land Rover - is now stuck in a snowdrift. 
Although it would be generous of me to stop, it seems clear that my neighbour has no right to my assistance in these circumstances. I would not wrong him if I simply continued on my way. His right to assistance from me is conditional on his recognizing a reciprocal duty to assist me in comparable circumstances. By repudiating this duty he has forfeit his own right to assistance from me. This is consistent with the reciprocity theory of duties to assistance.

It might be objected that this is plausible in the case of relatively trivial interests, like the interest in being towed out of a snowdrift. But it might be denied that rights that protect profound interests like our interest in a minimally decent life - or our interest in life itself - can be forfeit. The following case shows this supposition to be false. Suppose my neighbour is a notorious anti-Semite. He constantly tells me that he wishes that I, and my kind, would disappear from the face of the earth. While he will abide by the criminal law and does not threaten to physically attack me, he makes it clear that he would not lift a finger to help me. One day I pass my neighbour fishing by the canal, and he immediately launches into an hysterical tirade. Brandishing a document, he says that he has just come from his solicitor where he has established a legally binding mandate prohibiting any of his property, agents, or dependents from assisting me in any way, even if such assistance were necessary to 
preserve my life. At that very moment he falls into the canal, and, being unable to swim, begins to drown. I am standing near the life preserver and could easily save his life by throwing the preserver, at no cost to myself. Does the neighbour have the right that I save his life?

It is important to be clear about different potential sources of a duty to throw the life preserver. Perhaps the neighbour has children or other dependents who would suffer were he to die. It is plausible that they may have a right to my assistance that grounds a duty to rescue the neighbour. Similarly there may be virtue-oriented reasons for acting. To save the neighbour would be gracious and generous, whereas allowing him to drown would be petty, vindictive, and mean-spirited. In purely consequentialist terms, there is also a compelling case for rescue. The goods that can be realized by throwing the preserver (not only the saving of a life, but also potentially bringing about a transformation in his bigoted attitudes) hugely outweigh the costs. All of these reasons may ground a strong duty to rescue the neighbour. But what is hard to believe is that the neighbour himself has a right that I rescue him - that if I failed to throw the preserver I would be wronging him by treating him in a way that he a right not to be treated. By renouncing any reciprocal duty to assist me in comparable situations, the neighbour has forfeit his own right to assistance. 
Forfeiture cases such as these powerfully rebut the Razian conception that rights are always grounded in interests sufficient to hold others to a duty. In the present case the neighbour has a profound interest in continuing to live, I have the capacity to secure his interest, and the costs that I would have to bear in doing so are negligible. But these interestrelated considerations are not sufficient for holding me to a duty. The neighbour has no right to assistance that I would breach by failing to act.

In contrast, the reciprocity theory can explain why rights can be forfeit in cases like the above. Certain rights to assistance are centrally grounded in the recognition of a reciprocal duty to assist others in comparable circumstances. Where such recognition is absent, so to is the right.

As in the case of rights against harm, we must enquire whether the conditions for the possession and forfeiture of rights within the reciprocity theory are coherently integrated in the explanatory account. Once again the answer is yes. Both the conditions for possession of rights to assistance and the conditions for their forfeiture are explained by the underlying moral principle of reciprocity that states that we are deserving of consideration and respect because, and to the extent, that we give consideration and respect to others. As in the case of rights against harm, the reciprocity theory of rights to assistance thereby explains in an integrated manner both the grounds of the right - why we have it - and 
the conditions for the possession and loss of the right.

It might be objected that the 'duties' arising out of reciprocally recognized undertakings to assist are merely a form of prudential selfinterest (you will be better off in the long run if you assist others in their hour of need) or a means of facilitating aggregate welfare for a community (everyone will be better off in the long run if they assist others). Relationships of mutual preparedness to assist certainly are often supported by prudential and consequentialist reasons of this kind. But this is not the whole story. A person who credibly undertakes to assist me were I to be in need, places me under a reciprocal obligation to provide comparable assistance in similar circumstances. This is the case, independent of the balance of prudential and consequentialist reasons.

The differential stringency of rights against harm and rights to assistance

I have so far argued that certain central interpersonal rights are best understood as grounded in moral reciprocity relations between agents. The reciprocity theory has an advantage over rivals, such as the interest theory, in that it can better explain the dynamic nature of rights: the way that rights can be generated or forfeit by complying or failing to comply with the obligations we owe to others.

I will now explore a second important advantage of the reciprocity 
theory: its ability to explain the differing stringency between rights against harm and rights to assistance, and also the differing stringency of rights to equivalent forms of assistance held by different classes of agents. This will return us to Fabre's argument about resource wars.

I noted above that rights against harm appear to be more stringent than rights to assistance in two critical respects. Duties not to inflict significant harms such as death or severe attacks on bodily integrity can be enforced through lethal means. Second, duties not to harm can be enforced through acts of private self-defence (without the prior consent of a superior public authority). As we saw, common intuitions and legal precedent suggest that neither claim is true of rights to assistance. But why should this be?

A familiar argument for why duties not to harm are more stringent than duties to assist is that the cost of compliance for the former is lower than for the latter. All that the duty not to harm requires of us is to abstain from harmful or threatening acts, whereas the duty to assist requires positive and often costly agency. However this thought is both wrong and misleading. It is wrong because fulfilling duties not to harm can in fact impose far greater compliance costs than could justifiably be imposed by a duty to assist. Consider familiar cases in which you can avoid death only by killing an unrelated innocent bystander (for example 
if the only way to save oneself from a wrongful aggressor was by using an innocent bystander as a human shield). In such a situation observing one's duty not to harm the bystander requires the sacrifice of one's life. The duty not to kill is so stringent that, even when the right-bearer is a stranger, it can generate a duty to suffer death as the cost of compliance. Contrast this with the sacrifice that can be reasonably required to fulfil a duty to assist a stranger. It is difficult to imagine any circumstance in which a duty to assist a stranger could require the sacrifice of one's own life. (As will be discussed bellow, duties to assist family members, loved ones, or those who have rendered life saving services to us in the past can, in contrast, impose great obligations of sacrifice.)

This example shows how misleading is the traditional argument that the stringency of duties not to harm is grounded in their lower compliance costs. In fact, precisely the opposite is the case. The capacity to impose higher compliance costs on duty bearers is one important feature of the greater stringency of duties not to harm. The challenge is to explain why it is reasonable to impose higher costs as the price of complying with duties not to harm, compared with duties to assist.

This is a difficult question to answer on many theories of rights. Obviously the interest theory is not conducive to explaining these phenomena. If a duty not to harm and a duty to assist are both equally 
grounded in the rights-bearer's interest in continuing to live, then it is mysterious why the one duty can impose greater compliance costs on the duty holder than the other. But other prominent accounts also struggle. For example, the 'distributive justice' theory of self-defence pioneered by Phillip Montague and implicitly endorsed by a number of theorists including Jeff McMahan, claims that when wrongful harm will inevitably fall on someone, justice demands that it fall on the person responsible for the wrongful harm. ${ }^{25}$ But in the innocent bystander case neither you (the victim of attack) nor the bystander is responsible for the prospective wrongful harm. Why should justice require that you sacrifice your life as the cost of not killing the bystander? Why not simply toss a coin to determine who should receive the harm, or say that it is morally arbitrary where the harm falls?

In contrast, the reciprocity theory has a very simple explanation for why you are required to not kill the bystander even at the cost of sacrificing your own life. You owe the bystander the consideration of not killing

\footnotetext{
${ }^{25}$ Montague P., "Self-Defense and Choosing Between Lives", Philosophical Studies, Vol.40, 1981, pp. 207-219. The term 'distributive justice theory' is Whitley Kaufman's and he provides a useful critical discussion of it: "Torture and the "Distributive Justice" Theory of Self-Defense: An Assessment", Ethics and International Affairs, 22(1), 2008, 93-115.
} 
him, because he is extending the same consideration to you. Your obligation to him stems from the fact that he is at this very moment complying with the requirements of your right to life - and that is something of immense value and importance for you. You therefore owe him the reciprocal duty.

The highly stringent nature of rights against harm is, therefore, linked to the distinctive character of the reciprocity relations that underlie them. As we have seen rights against harm are grounded in a reciprocity of actual compliance. This reciprocity of compliance has a contemporaneous and an historical element. You can possess rights because you have satisfied the conditions of compliance for the rights of others in the past or, as in the paradigm case of the right to life, because you are satisfying the conditions of compliance for the rights of others at this very moment. Thus I currently possess the right that you not kill me, because I am at this moment complying with your right that I not kill you. The right against lethal harm is rooted in contemporaneous actual compliance and this is what gives it its distinctive stringency.

At this point we must face an important objection. It is a well-known weakness of the will theory of rights that it has great difficulty in ascribing rights to incompetents since the theory holds that rights can only be held by agents capable of exercising powers. It might seem that 
the reciprocity theory suffers from a similar weakness since it insists that agents possess certain rights because and to the extent they comply with the rights of others. But complying with the rights of others might seem to require the performance of acts and omissions with the intention of conforming to the requirements of the right. In that case we could not ascribe rights to infants, the mentally disabled, the comatose and the unconscious who are not capable of such agency. A related problem might seem to befall the attribution of rights against harm to persons who do not know of our existence or have no capacity to inflict harm on us. Can such persons really said to be complying with our right not to be harmed in a way that could ground reciprocal obligations to them?

But the reciprocity theory does not suffer from the same weakness as the will theory with respect to rights against harm. This is because it is perfectly possible to comply with a negative duty, without intentional agency or the capacity for non-compliant action. To see this consider the following case: You and I have adjoining gardens and there is no regulation governing when we may mow our lawns. However I am having a garden party on Saturday and I ask you to undertake not to mow your lawn during the party. I agree to pay you $\$ 50$ provided you have complied with your undertaking. What are the conditions for your having complied in such a way as to generate and obligation on me to 
compensate you? The answer is simply that you not mow during the specified time. What if you take a nap for most of Saturday afternoon so that you are performing no intentional act or omission during this time? Clearly while you are napping you are still in compliance with your obligation not to mow. What if you have a fall on Friday evening and spend the whole of Saturday unconscious in hospital so that you have no material capacity to violate your obligation? Again you are still clearly in compliance with your obligation in such a way as to merit the resulting compensation. Compliance with an obligation to abstain from (harmful) behaviour does not require the capacity for intentional agency, or even the capacity for any agency at all. Compliance with a negative obligation when you are in a state of incompetence is not onerous (indeed noncompliance may be physically impossible), but this does not mean that the compliance is not genuine, nor that such compliance is incapable of grounding reciprocal obligations on others.

That being said, it is clearly not the case that any non-performance of harmful action is sufficient to generate a reciprocal right against harm. The loaf in my kitchen is not currently slicing me in two (nor has it ever done so) but it does not thereby acquire a right against being sliced in two. If an individual is to comply with a negative duty in such a way as to acquire a reciprocal right, then it must be a being of the kind that is 
capable of possessing rights and duties, and it must actually possess such a duty. Human beings are beings of this kind. Humans are capable of having duties not to harm others and they do actually possess such duties. Moreover they continue to be subject to such duties - and to be in compliance with them - while they are sleeping, comatose or otherwise in a state of incompetence.

We have seen that rights against harm possess the stringency they do because they are rooted in a reciprocity relationship of actual compliance to mutual obligations. As we noted above, the reciprocity relations underlying rights to assistance have a different character, and this explains their lesser stringency. Rather than being rooted in a reciprocity of actual compliance, they instead typically stem from a reciprocity of expected future compliance. Most of the people we are called on to assist are not currently assisting us and nor they have assisted us in the past. Instead, the obligation to assist others arises from the fact that they acknowledge a reciprocal obligation to assist us in comparable circumstances in the future. The reciprocity relationship underlying rights to assistance is prospective and moreover it is conditional (he acknowledges an obligation to assist me were I to be in need). This prospective and conditional reciprocity grounds a genuine duty, but it lacks the stringency that derives from the reciprocity of actual 
compliance that we find underlying rights against harm because it is merely a reciprocity of expected compliance.

The difference between these two forms of reciprocity is both epistemic and ontological. It is a matter of objective fact whether you are currently complying or failing to comply with my rights against harm or have done so in the past. Moreover, I can know with near certainty that you are currently complying with my right to life, because it is quite obvious that you are currently making no attack on my person. ${ }^{26}$ But it may be impossible, even in principle, to determine now whether you will assist me at some point in the future, since this depends on your future free decisions. Certainly I can know your preparedness to assist me in the future with a much weaker degree of certainty than I can know your current or prior compliance with your duty not to harm me.

Sometimes of course, duties to assist may arise not from expected future assistance, but from actual past assistance. In such cases we find that the right to assistance is indeed more stringent (and may be comparably stringed to rights against harm) precisely as the reciprocity theory predicts. For example suppose you saved my life in the past. It would be natural to say that 'I owe you my life' and that I would be obligated to ${ }^{26}$ I say 'near certainty' because it is conceivable that you are currently engaged in an unexpected secret conspiracy on my life. 
bear significantly higher costs in the course of rescuing you, than if you had not assisted me in the past in this way. Indeed, although we are not ordinarily obligated to sacrifice our own life to save others, it is plausible that I may be obligated to sacrifice my own life if this were necessary to rescue you (countless movies have turned on this supposition).

The reciprocity theory can explain not only the differing stringency between rights against harm and rights to assistance. It can also explain why identical interests and needs can generate significantly different duties to assist in differing classes of agents. For example we have stronger duties to assist those with whom we share special relationships than we do to assist strangers, even when the needs are the same. That makes sense from the perspective of reciprocity. On this theory, the strength of the duty to assist depends on the expectation of future reciprocal assistance in comparable circumstances. But that in turn depends on the strength and depth of social relationships. I know with great intimacy what forms of support and assistance my close friends will provide to me in moments of need. This knowledge guides and supports the interlocking obligations of care and consideration that are partially constitutive of friendship. The same is true with my family. That is why duties of care for friends and family are so strong. With strangers I have far less reason to believe that they recognize, and are ready to act upon, a 
stringent obligation of assistance towards me in comparable circumstances. $^{27}$

Nonetheless we can have duties to assist strangers. Most obviously we can have strong duties to assist strangers who are compatriots, through participating in public welfare institutions. The reciprocity theory can explain these duties and moreover why these duties can be stronger than duties owed to non-compatriot strangers. Legal regimes play a decisive role in enabling duties of assistance between strangers. Once a duty to assist is legally enforced (for example through a compulsory social insurance scheme), that very fact provides a strong reason, that would otherwise not exist, to expect that others within the regime will contribute towards assisting me should I be in need. This explains why duties to assist can be justifiably enforced through public institutions. The

\footnotetext{
${ }^{27}$ One might accept that we owe strong duties to friends and families, but balk at the attribution of correlative rights. Many believe that it is inappropriate to extend rightstalk to intimate relationships. This seems to me a mistake. It is certainly true that within a well functioning intimate relationship rights will be eclipsed by other more care oriented and superogatory normative considerations - an intimate relationship in which members constantly need to 'stand on their rights' is not a healthy one. Nonetheless it is natural to say that a person whose intimate partner accepts consideration, care, and respect from them has the right to expect the same in return. I am grateful to Leif Wenar and Massimo Renzo for raising this issue.
} 
mechanism of enforcement is itself partially generative of the very duty it enforces. That is to say, by making it the case that I that my compatriots can be relied on to contribute to assisting me in moments of need, legal enforcement generates a moral obligation for me to contribute towards provision for their need. This fact, in turn, explains why, other things being equal, we have a greater duty to assist compatriots than foreigners. The reasons need have nothing to do with metaphysical notions of blood and identity. It is rather because of the very concrete way in which law enforces prospective reciprocity among members of a community, and thereby generates duties of assistance between them.

For strangers who are not compatriots within a shared legal framework, the basis of expected future reciprocity rests on something more tenuous a shared presumptive understanding of common humanity. We rightly assume that most people are prepared to assist others in cases where the need is high and the cost of assisting is low. To be sure, we cannot be certain that all persons will recognise such an obligation, and clearly some do not. But knowing what we do of humanity (in both ourselves and in others) it is a reasonable presumption, at least until defeated by further evidence. This is why I had to tell such a peculiar story in the antiSemite case to make plausible the forfeiture of a right to costless assistance. This defeasible presumption is sufficient to ground a duty to 
assist. The shape of this duty conforms to the intuitive shape of our duty to assist strangers with whom we share no publically enforceable institutional arrangement - we have the duty to assist in cases where the need is great and the costs of assistance are low.

So the reciprocity theory can explain a raft of commonly held intuitions about the stringency of rights and duties. Duties not to harm are extraordinarily stringent because they derive from reciprocity in actual compliance of mutual obligations. Duties to assist are weaker because they are grounded in an expectation of expected future compliance with mutual obligations. They are weaker still when shared social relations are tenuous and there is no shared legally binding enforcement mechanism.

This same family of considerations explains why duties not to harm are privately and lethally enforceable whereas duties to assist are typically not. The global poor can have rights to assistance from the affluent. But those rights have a different character to the rights against harm that can generate rights of lethal private defence. When someone makes an unjustified attack on your life they attempt to kill you at the very moment that you are complying with their right not to be killed. The stringency of the duty explains the exceptional permission to enforce the duty through private lethal defence. 
When someone who is under a duty to provide assistance to a stranger fails to do so, the harmful effects may be identical to unjustified aggression, but the source and stringency of the duty is different in at least this respect: There is no concurrent relationship of reciprocal compliance underlying the duty to assist - the poor do not at this moment provide life giving assistance to the affluent.

In fact, there seems to be a close congruence between the harms we can be obligated to bear as a consequence of complying with a duty, and the harms that we can permissibly inflict on another to prevent his breaching a duty (they may, indeed, be correlative). As we have seen in the innocent bystander case, I can be obligated to sacrifice my own life as a consequence of fulfilling the duty not to kill a stranger. This is congruent with the permission to kill a person who responsibly breaches the duty not to kill another. But no one is obligated to sacrifice their own life as a consequence of fulfilling a duty to assist a stranger when they are not themselves responsible for the stranger's plight and where the stranger has not rendered life preserving services to them in the past. Similarly it is impermissible to enforce compliance with a duty to assist by killing the person who threatens to breach that duty. Subsistence killing, let alone 
subsistence wars, are impermissible. ${ }^{28}$

\section{Conclusion}

How comprehensive an account of rights can the reciprocity theory provide? This remains an open question. Above, I described the class rights I wished to explain as 'interpersonal rights'. It is time to say more about what I take this to mean. Interpersonal rights may be contrasted with institutional rights. Institutional rights can only be held within a social and political order and are necessarily mediated by social institutions; in particular institutions of government. We could not make sense of the possession or assertion of institutional rights within the state of nature. Paradigm examples of institutional rights include procedural rights (for example due process rights) and political rights (for example rights of democratic participation).

\footnotetext{
${ }^{28}$ Numerous case-generated intuitions powerfully support this conclusion: Tax evasion is not permissibly enforced with the death penalty, even if shortfalls resulting from unpaid tax would foreseeably result in the deaths of several persons. The Oxfam representative who rightly tells me that I have a moral duty to donate money to save the lives of impoverished persons in the third world does not act permissibly if he threatens to shoot me in the head when I tell him that I will instead spend the money on book of moral philosophy.
} 
Interpersonal rights are Hohfeldian relations between persons that can exist independently of a social and political order (we can conceive of them existing in the state of nature). In this sense they are normatively prior to institutional rights. The paradigms of interpersonal rights - and those most conducive to the reciprocity theory - are rights of bodily integrity and self-ownership: the rights not to be killed, attacked, or tortured. Although I have not been able to argue the case here, liberty rights, privacy rights, and rights to freedom of expression and conscience also fit the reciprocity paradigm. These are some of our most important human rights, but interpersonal rights can also include less fundamental moral rights, for example the right to be treated with courtesy and consideration, and the rights and duties of friendship. As we have seen, interpersonal rights grounded in reciprocity can include rights to assistance as well as rights against harm.

Not all rights fit easily within one of these categories. Property rights, for instance, contain certain characteristics of interpersonal and institutional rights (because the contours of property ownership are fundamentally embedded in social and legal arrangements). While the reciprocity theory is most conducive to interpersonal rights, our discussion of how mandatory social insurance schemes can be grounded in positive reciprocity relations shows that some institutional rights can also be 
amenable to a reciprocity analysis. It may be that the scope of the reciprocity theory can be further expanded into the institutional domain by investigating the role of complex and mediated reciprocity relations within social institutions. On the other hand certain rights will almost certainly resist explanation within the reciprocity paradigm because they are non-forfeitable (due process rights are a clear example).

Similarly, certain rights to assistance will be challenging for the reciprocity theory because the agent to whom the duty is owed may not be in a position ever to reciprocate assistance. Intergenerational rights also present distinctive difficulties, although transitive and asynchronous reciprocity relations may enable us to get traction on certain intergenerational rights (consider how parents who neglect their children in youth may forfeit the right to be cared for by them in old age). All of these issues require considerable further work and development. To the extent that genuine classes of right resist explanation within the reciprocity theory, we will be required to adopt a pluralistic account of rights in which reciprocity relations are one ground of rights among others.

It should be noted that I have here developed the reciprocity account of rights as an alternative to other standard accounts, most notably the interest theory. But this account is not incompatible with those others, 
and it may therefore be viewed as a supplement rather than an alternative to them. Suppose it were true that the duty not to kill and the duty to provide minimal resources to the poor have a common source in the interest all humans have in leading a minimally decent life. There would still be this significant difference between them: the right not to be killed is additionally underpinned by a moral relationship of concurrent reciprocal compliance, whereas the right to assistance is not. This difference can explain the many intuitive differences between duties not to harm and the duty to assist, including why the right not to be harmed is lethally and privately enforceable whereas the right to be assisted is, in general, not. 